\section{Increasing Resident Physician Well-Being through a Motivational Fitness Curriculum: A Pilot Study}

Ruth Nutting, Ph.D.1,2, Justin T. Grant, D.O.,2,

Samuel Ofei-Dodoo, Ph.D., MPA, M.A.', Matthew S. Runde, D.O.,2, Kethlyn A. Staab, M.A. ${ }^{2}$, Barret R. Richard, M.D. ${ }^{1,2}$

University of Kansas School of Medicine-Wichita, Wichita, KS

'Department of Family and Community Medicine

${ }^{2}$ Family Medicine Residency Program at Ascension Via Christi

Received April 9, 2020; Accepted for publication.June 30, 2020; Published online Sept. 11, 2020

\section{ABSTRACT}

Introduction. Healthcare professionals who participate in regular exercise better manage job related stressors, utilize fewer sick days, and discuss fitness with patients at increased rates. Although resident physicians are aware of the health benefits of exercise their rates of exercise are much lower than among medical trainees and practicing physicians. Resident physicians have reported lack of time for traditional structured workouts as one of the greatest barriers to fitness. This study sought to increase resident physician well-being by providing brief workouts through a motivational fitness curriculum.

Methods. This pilot study utilized a nonexperimental design; a pre-/ post-intervention consisted of a 10-month motivational fitness curriculum. Thirteen family medicine residents at a training program in the midwestern United States participated in this study. The Depression Anxiety Stress Scale-21 (DASS-21) and the Abbreviated Maslach Burnout Inventory (MBI-9) were used to measure the participants' well-being, pre- and post-curriculum. Standard descriptive statistics and paired samples t-test were used to analyze the data.

Results. Twenty-eight percent (13/36) of eligible first-year and second-year family medicine resident physicians participated in the study. On the DASS-21, study participants displayed an improvement in depression, anxiety, and stress scores post-curriculum. On the MBI-9, the participants reported decreased score in emotional exhaustion, but there were no changes in depersonalization and personal accomplishment scores over time.

Conclusion. A motivational fitness curriculum may be a convenient way to support well-being among resident physicians. These findings were salient, as graduate medical education programs can implement similar initiatives to support resident physicians' psychological and physical well-being. Kans J Med 2020;13:228-234

\section{INTRODUCTION}

Excessive workload, clerical burden, decreased control over workload, struggles with work-life integration, and dissolution of meaning in work are factors that are associated with burnout. ${ }^{1,2}$ Over $50 \%$ of University of Kansas School of Medicine-Wichita (KUSMW) resident physicians experienced at least one manifestation of burnout in 2017.2 Throughout the U.S., declining psychological health related to learner depression and burnout has led graduate medical educators to instill trainees with interpersonal skills and personal well-being habits. ${ }^{3}$ These interventions have targeted increasing learner confidence, satisfaction, self-validation, tolerance,
KANSAS JOURNAL of MEDICINE

and compassion., ${ }^{3,4}$ Although somewhat effective, these efforts fall short in accounting for the value of exercise on resident well-being. ${ }^{4-6}$ Healthcare professionals who participate in regular physical activity manage job related stressors better, utilize fewer sick days, and discuss fitness activities with patients at increased rates.-6

In addition, resident physicians experiencing positive mental and behavioral health are more satisfied with their jobs, make fewer errors, and display increased levels of empathy. Experiencing positive mental and physical health leads to better patient care; patient compliance increases and positive health related outcomes are experienced. ${ }^{4,710}$ Although resident physicians are aware of the health benefits of physical activity, resident physicians exercise less than medical students and practicing physicians. ${ }^{4-6,11}$ Resident physicians have reported lack of time for traditional structured workouts as being the greatest barrier to fitness. ${ }^{4}$ Given these findings, the current study sought to provide a motivational fitness curriculum targeted at providing workouts adaptable to the time constraints of residency to promote resident well-being.

\section{METHODS}

Study Design. This pilot study involved 13 first- and second-year family medicine residents at a training program in the midwestern United States. The KUSM-W Institutional Review Board approved the study. A sample size of 13 was calculated as necessary for adequate power $(>0.75)$ to detect significant group differences among the variables with 0.8 effect size and $\mathrm{p}<0.05 .{ }^{12}$ A motivational fitness curriculum was created by one of the authors (JTG), who had experience with fitness programming. This curriculum was provided to the participants (see Appendix A) as an intervention.

This curriculum consisted of three, 30-minute, high-intensity workouts (see Appendix B) per week for ten months (from September 2018 and June 2019). The workouts could be done independently or with others and required minimal equipment that could be purchased or made available with a gym membership. Workout activities were provided in a GroupMe chat where participants could post their times and repetitions. In addition, articles, books, and podcasts on physical, psychological, spiritual, and financial wellness were provided to the participants. Depression Anxiety Stress Scale-21 (DASS-21)13-15 and the Abbreviated Maslach Burnout Inventory (MBI-9)1,16-18 were used to measure participants' well-being, pre-/ post-curriculum.

Study Instruments. Each survey consisted of the two validated measures: the DASS-21 and MBI-9. The baseline survey also included demographic questions such as age, gender, and post graduate year. Participants were asked to provide general comments and feedback regarding the curriculum during the post-intervention data collection. 
KANSAS JOURNAL of MEDICINE

INCREASING RESIDENT PHYSICIAN WELL-BEING continued.

Depression, Anxiety, Stress. The DASS-21 consists of 21 questions in three scales designed to measure negative emotional states of depression, anxiety, and stress. ${ }^{13-15}$ These scales have been found to have high internal consistency and can be used in a variety of settings to measure current state or changes over time. ${ }^{19}$ Participants recorded how much a statement applied to them over the past week on a 4-point Likert scale $(0=$ Never, $3=$ Almost Always). Scores for the seven questions specific to each of the three scales were summed with a possible score ranging from zero to 21. Higher scores indicate greater levels of the emotional state.

Burnout. The MBI-9, a validated 9-item questionnaire, is considered a criterion tool to measure manifestations of burnout among health care professionals, including physicians, medical trainees, and nonclinical professionals., ${ }^{2,15-18}$ The inventory assesses professional burnout across three dimensions: emotional exhaustion, depersonalization, and perception of personal accomplishment. Participants recorded their feelings for each item on a 7-point rating scale $(0=$ Never, $6=$ Every day $)$. Scores for the three questions specific to each of the dimensions were summed with a possible score ranging from zero to 18 . We conceptualized burnout as a continuous variable along a spectrum ranging from low to high experienced feelings. For the emotional exhaustion and depersonalization dimensions, higher scores are indicative of greater emotional exhaustion and depersonalization, and greater burnout. For the personal accomplishment dimension, higher scores indicate a greater sense of personal accomplishment, and less burnout.

Statistical Analysis. Standard descriptive statistics and paired samples t-test were performed to analyze the quantitative data. All analyses were 2 -sided with alpha of 0.05. The IBM SPSS (Statistical PackagefortheSocialSciences),version26wasusedfortheseanalyses.

Qualitative Analysis. Two of the authors (RN and SO-D) used a phenomenological approach to analyze the open-ended responses. This approach focused on the commonality of a lived experience within a group to develop a description of the nature of the phenomenon. ${ }^{20}$ The researchers were intentional to convey the overall essence of participants' experiences by incorporating description and context.

\section{RESULTS}

Twenty-eight percent (13/36) of eligible first-year and second-year family medicine residents participated in this study. The average age of the participants was 29.5 years $(\mathrm{SD}=2.4) ; 54 \%(7 / 13)$ were males and $46 \%(6 / 13)$ were females; $62 \%$ (8/13) were first-year resident physicians and $38 \%$ (5/13) were second-year resident physicians. On the DASS-21, study participants displayed an improvement in depression, anxiety, and stress scores post-curriculum (Table 1). On the MBI-9, the participants had a decrease in emotional exhaustion score but there were no changes in depersonalization and personal accomplishment scores over time (Table 1).

Narrative Feedback. Analysis of the open-ended responses showed that the participants had a positive feedback regarding the wellness intervention. Three major themes emerged: unique and convenient workouts, motivational environment, and time constraints as a continued barrier (Table 2). Resident physicians identified the workouts as convenient and engaging as there were three unique workouts provided each week. Motivation and a sense of community were fostered through participants posting their workout times and scores, as well as pictures of their workouts on the GroupMe application. Conversely, some participants felt a sense of guilt during the weeks their participation was lower due to residency related time restrictions.

Table 1. Outcome scores of surveys before and after the curriculum.

\begin{tabular}{|c|c|c|c|c|c|}
\hline & \multicolumn{2}{|c|}{ Time point ${ }^{\mathrm{a}}$} & & & \\
\hline $\begin{array}{l}\text { Subscale } \\
\text { (possible } \\
\text { range) }\end{array}$ & $\begin{array}{c}\text { Pre- } \\
\text { curriculum } \\
(\mathrm{N}=13)\end{array}$ & $\begin{array}{c}\text { Post- } \\
\text { curriculum } \\
(\mathrm{N}=13)\end{array}$ & $\mathbf{t}$ & $\begin{array}{c}\mathbf{p} \\
\text { value }\end{array}$ & $\begin{array}{c}\text { Mean } \\
\text { difference } \\
(95 \% \mathrm{CI})\end{array}$ \\
\hline $\begin{array}{l}\text { MBI-9 } \\
\text { Emotional } \\
\text { Exhaustion } \\
(0-18)\end{array}$ & $11.0(4.4)$ & $10.1(5.2)$ & -0.71 & 0.048 & $\begin{array}{l}-0.9(-3.4 \text { to } \\
1.7)\end{array}$ \\
\hline $\begin{array}{l}\text { MBI-9 } \\
\text { Deperson- } \\
\text { alization } \\
(0-18)\end{array}$ & $6.4(3.8)$ & $6.8(4.3)$ & 0.45 & 0.704 & 0.4 (-1.9 to 2.9$)$ \\
\hline $\begin{array}{l}\text { MBI-9 } \\
\text { Personal } \\
\text { Accom- } \\
\text { plishment } \\
(0-18)\end{array}$ & $13.6(2.6)$ & $13.7(2.5)$ & -0.08 & 0.935 & $0.1(2.3$ to 2.1$)$ \\
\hline $\begin{array}{l}\text { DASS-21 } \\
\text { Depression } \\
(0-21)\end{array}$ & $8.4(10.8)$ & $6.7(6.9)$ & -0.54 & 0.048 & $\begin{array}{l}-1.6(-8.4 \text { to } \\
5.1)\end{array}$ \\
\hline $\begin{array}{l}\text { DASS-21 } \\
\text { Anxiety } \\
(0-21)\end{array}$ & $6.5(5.6)$ & $3.8(4.7)$ & -1.68 & 0.046 & $\begin{array}{l}-2.6(-5.4 \text { to } \\
0.7)\end{array}$ \\
\hline $\begin{array}{l}\text { DASS-21 } \\
\text { Stress (O- } \\
21)\end{array}$ & $12.2(8.8)$ & $8.0(6.1)$ & -2.05 & 0.042 & $\begin{array}{l}-5.2(-8.6 \text { to } \\
0.3)\end{array}$ \\
\hline
\end{tabular}

MBI-9 = Abbreviated Maslach Burnout Inventory. DASS-21 = Depression Anxiety Stress Scales-21.

Notes: On MBI-9, higher scores on the Emotional Exhaustion and Depersonalization subscales, and lower scores on the Personal Accomplishment subscale indicate greater burnout. On the DASS-21 subscales, higher scores indicate greater levels of that emotional state.

aValues shown are mean score (SD).

\section{DISCUSSION}

The findings suggested that a motivational fitness curriculum consisting of brief, high-intensity workouts may improve emotional exhaustion, symptoms of depression and anxiety, and stress among resident physicians. Resident physicians who participated in the motivational fitness curriculum experienced decreased symptoms of depression, anxiety, and overall stress, and emotional exhaustion decreased. This was crucial because although prior studies have shown that residents were aware of the benefits of physical activities, the rates they have been exercising were lower compared to medical students and practicing physicians. ${ }^{4-6}$ 


\begin{tabular}{|c|c|}
\hline Themes & Significant Statements \\
\hline $\begin{array}{l}\text { Theme 1: Unique and Convenient } \\
\text { Workouts. } \\
\text { The motivational fitness curricu- } \\
\text { lum provided residents with three } \\
\text { physically and mentally rewarding } \\
\text { workouts per week. Participants } \\
\text { identified that the workouts were } \\
\text { feasible and alleviated the need to } \\
\text { spend time deciding on workouts } \\
\text { to complete. }\end{array}$ & $\begin{array}{l}\text { 1. "Good, quick workouts that } \\
\text { helped me get a workout in when I } \\
\text { had a small amount of time." } \\
\text { 2. "It was great to have new work- } \\
\text { outs throughout the week." } \\
\text { 3. "I enjoyed receiving three work- } \\
\text { outs per week, so I didn't have to } \\
\text { think about what I was going to do } \\
\text { at the gym.” }\end{array}$ \\
\hline $\begin{array}{l}\text { Theme 2: Motivational Environ- } \\
\text { ment. } \\
\text { With utilization of the GroupMe } \\
\text { application, community and } \\
\text { motivation were fostered through } \\
\text { participants posting their work- } \\
\text { out pictures and times/scores. } \\
\text { Whether or not residents were } \\
\text { able to engage in all three workouts } \\
\text { each week, they continued to feel } \\
\text { encouraged by participants' posts. }\end{array}$ & $\begin{array}{l}\text { 1. "It was great motivation knowing } \\
\text { others were doing great workouts } \\
\text { as part of a community." } \\
\text { 2. "I was encouraged to see the } \\
\text { results of other participants". } \\
\text { 3. "It was great to see others do } \\
\text { well. That was motivation for me." }\end{array}$ \\
\hline $\begin{array}{l}\text { Theme 3: Time Constraints as a } \\
\text { Continued Barrier: } \\
\text { Time constraints created a barrier } \\
\text { to completion of all three weekly } \\
\text { workouts. With decreased comple- } \\
\text { tion rates, a sense of guilt could be } \\
\text { experienced. }\end{array}$ & $\begin{array}{l}\text { 1. "I sometimes chose easier work- } \\
\text { outs for time and learning ease." } \\
\text { 2. "I participated some weeks } \\
\text { more than others." } \\
\text { 3. "I felt guilt when there wasn't } \\
\text { time to get a workout in." }\end{array}$ \\
\hline
\end{tabular}

Though several academic studies have shown the benefits of physical activity among physicians, ${ }^{4-6}$ this study demonstrated potential benefits of a motivational fitness curriculum that consisted of brief, high-intensity workouts to improve the well-being of resident physicians, while simultaneously providing a sense of community through a mobile application. The findings are of pertinence as graduate medical education programs nationally have increased well-being initiatives for resident physicians. To assist graduate medical education programs in implementing similar well-being initiatives, a detailed description of the exercise curriculum and sample workouts are provided in the appendices. Exercise programs will likely be most successful when championed by a resident or a fellow physician, due to increased buy-in from peers. In addition, it is paramount that this champion is well educated in fitness regimens to develop engaging workouts that are physically safe and effective for all participants.

This study was limited by having been conducted in a single residency program. The small sample size and nonprobability-based nature of the convenience sample limit generalizability of the findings. Also, there was a potential for sample bias in residents who participated in this study. The residents with the least amount of time, greatest burnout, and most emotional distress may not have participated in the study. In addition, social desirability bias may limit the findings of the study as respondents' responses to the survey questions might not be reflective of their true thoughts or feelings. The lack of control group makes it difficult to infer causation and reduces generalizability as there was no way to know if the improvements were linked directly to the motivational fitness curriculum. Additional research is warranted. A prudent next step would include implementing a motivational fitness curriculum in multiple residency programs (both family medicine and other
KANSAS JOURNAL of MEDICINE INCREASING RESIDENT PHYSICIAN WELL-BEING continued.

residency programs) to see how the effects of the curriculum compared across different specialties. Given the exploratory nature of the study, the statistical findings should be viewed cautiously.

\section{CONCLUSIONS}

In conclusion, the findings suggested that a motivational fitness curriculum consisting of brief, high-intensity workouts provided a convenient way to reduce depression, anxiety, stress, and emotional exhaustion among resident physicians. The improvement in resident physicians' mental and behavioral health potentially could translate to better patient care as a result. These findings are salient, as graduate medical education programs can implement similar initiatives to support resident physicians' psychological and physical well-being.

\section{REFERENCES}

${ }^{1}$ Shanafelt TD, Dyrbye LN, West CP. Addressing physician burnout: The way forward. JAMA 2017; 317:901-902. PMID: 28196201.

2 Ofei-Dodoo S, Callaway P, Engels K. Prevalence and etiology of burnout in a community-based graduate medical education system: A mixed method study. Fam Med 2019; 51(9):766-771. PMID: 31596935.

3 Bodenheimer T, Sinsky C. From triple to quadruple aim: Care of the patient requires care of the provider. Ann Fam Med 2014; 12:573-576. PMID: 25384822

${ }^{4}$ Fargen KM, Spiotta AM, Turner RD, Patel S. The importance of exercise in the well-rounded physician: Dialogue for the inclusion of a physical fitness program in neurosurgery resident training. World Neurosurg 2016; 90:380384. PMID: 27001240.

${ }^{5}$ Williams AS, Williams CD, Cronk NJ, Kruse RL, Ringdahl EN, Koopman RJ. Understanding the exercise habits of residents and attending physicians: A mixed methodology study. Fam Med 2015; 47(2):118-123. PMID: 25646983.

${ }^{6}$ Spiotta AM, Fargen KM, Denham SL, et al. Incorporation of a physical education and nutrition program into neurosurgery: A proof of concept pilot program. Neurosurgery 2016; 79(4):613-619. PMID: 27465847.

7 Goetz K, Musselmann B, Szecsenyi J, Joos S. The influence of workload and health behavior on job satisfaction of general practitioners. Fam Med 2013; 45(2):95-101. PMID: 23378076.

${ }^{8}$ Williams ES, Manwell LB, Konrad TR, et al. The relationship of organizational culture, stress, satisfaction, and burnout with physician-reported error and suboptimal patient care: Results from the MEMO study. Health Care Manage Rev 2007; 32(3):203-212. PMID: 17666991.

9 Hull SK, DiLalla LF, Dorsey JK. Prevalence of health-related behaviors among physicians and medical trainees. Acad Psychiatry 2008; 32(1):31-38. PMID: 18270278.

${ }^{10}$ Shanafelt TD, West C, Zhao X, et al. Relationship between increased personal well-being and enhanced among internal medicine residents. J Gen Intern Med 2005; 20(7):559-564. PMID: 16050855.

${ }^{11}$ Weight CJ, Sellon JL, Lessard-Anderson, CR, Shanafelt TD, Olsen KD, Lasowski, ER. Physical activity, quality of life, and burnout among physician trainees: The effect of a team-based, incentivized exercise program. Mayo Clin Proc 2013; 88(12):1435-1442. PMID: 24290117.

${ }^{12}$ Australia and New Zealand Melanoma Trials Group Statistical Decision Tree. Power calculator for Independent T-test or paired t-test. 2020. https:// www.anzmtg.org/stats/PowerCalculator/PowerTtest. Accessed March 23, 2020.

${ }^{13}$ Lovibond SH, Lovibond PF. Manual for the Depression Anxiety Stress Scales. 2nd ed. Sydney, Australia: Psychology Foundation, 1995.

14 Gomez F. A guide to the depression, anxiety, and stress scale (DASS 21). https://jeanmartainnaturopath.com.au/wp-content/uploads/2016/10/ Dass2l.pdf. Accessed March 23, 2020.

15 Ofei-Dodoo S, Cleland-Leighton A, Nilsen K, Cloward JL, Casey E. Impact of a mindfulness-based, workplace group yoga intervention on burnout, self-care, and compassion in health care professionals: A pilot study. J Occup Environ Med 2020; 62(8):581-587. PMID: 32358474. 


\section{KANSAS JOURNAL of MEDICINE}

INCREASING RESIDENT PHYSICIAN WELL-BEING

continued.

${ }_{16}$ Maslach C, Leiter MP. Early predictors of job burnout and engagement. J Appl Psychol 2008; 93(3):498-512. PMID: 18457483.

17 Ofei-Dodoo S, Ebberwein C, Kellerman R. Assessing loneliness and other types of emotional distress among practicing physicians. Kans J Med 2020;

13:1-5. PMID: 32047581.

${ }_{18}$ Ofei-Dodoo S, Scripter C, Kellerman R. Job satisfaction and burnout among nonclinical workers in a medical education center. Fam Med 2018; 50(3):223-227. PMID: 29537466.

19 Osman A, Wong JL, Bagge CL, Freedenthal S, Gutierrez PM, Lozano G. The Depression Anxiety Stress Scales-2l (DASS-21): Further examination of dimensions, scale reliability, and correlates. J Clin Psychol 2012; 68(12):1322-1338. PMID: 22930477.

${ }^{20}$ Creswell JW. Qualitative inquiry \& research design: Choosing among five approaches. 2nd ed. Thousands Oaks, California: SAGE, 2007.

Keywords: physical fitness, internship and residency, professional burnout, health, family practice 


\section{Motivational Fitness Curriculum}

\section{Introduction}

continued.

What is fitness? If you ask 10 different health or fitness "professionals," you will likely get 10 different answers. To me, fitness is the pursuit of health that allows one to enjoy a quality life that is not limited by one's inability to participate in its many opportunities. As healthcare "professionals" (yes, I used quotes for a reason), we stand on a prestigious platform to encourage change - lifelong, personal, community, national, and international change. We all know the benefits of healthy lifestyle affecting literally every disease process we study. But we are so unfit and unhealthy ourselves, that we as a medical community have become a poor conduit for true health information or leadership changing the choices of those brought into our care. Sure, we can check all the USPSTF boxes, keep our patients up to date on current recommended medications, and be available when they become sick; but can we actually lead our patients to truly healthier lifestyles if we ourselves never move except from hospital room to hospital room, always take the elevator, "fuel" ourselves with soda and pastries from the cafeteria, and manage our time so poorly that we never sleep? Residency is, without a doubt, hard. Next to being a husband and father, it is one of the hardest things I have ever done. So, why barely scrape by, gain 30 lbs., suffer through depression/anxiety, and finish residency feeling like all you've done is prescribe medications that only half of your patients take anyway?

Enter, Via Christi Family Medicine Residency's 13 block exercise curriculum. The goal of this curriculum is to help you, as the resident, pursue your own health so that you might not only enjoy life through these grueling years more, but so that you might become a better conduit for healthy life changes in your patients' lives. The curriculum will consist of workouts, reading, and cooking. Being such a large residency, it can even grow into a culture of pursuing health and excellence. I can think of no better way to conclude this introduction to inspire cultural change than by quoting Greg Glassman's Fitness in 100 Words.

"Eat meat and vegetables, nuts and seeds, some fruit, little starch and no sugar. Keep intake to levels that will support exercise but not body fat. Practice and train major lifts: deadlift, clean, squat, presses, C\&J, and snatch. Similarly, master the basics of gymnastics: pull-ups, dips, rope climb, push-ups, sit-ups, presses to handstand, pirouettes, flips, splits, and holds. Bike, run, swim, row, etc., hard and fast. Five or six days per week, mix these elements in as many combinations and patterns as creativity will allow. Routine is the enemy. Keep workouts short and intense. Regularly learn and play new sports.” - Greg Glassman, CrossFit Founder

\section{The Workouts}

There will be 3 workouts per week, not including Family Docs for Fitness (FDFF), which can be done on your own with minimal equipment. If you don't have access to any equipment, the workouts will have to be modified a good amount of time. I strongly encourage you to invest in yourself, get a gym membership, purchase some basic equipment like dumbbells or kettlebells, or find a friend who has equipment (my garage is open to the residency). Tuesday nights at 1800, FDFF workouts will be an optional 4 th workout for those who wish to join. These are one hour long or less, and everyone will be done no later than 1900. During these workouts, we will spend about 20 minutes learning the skills to properly lift - specifically, how to properly deadlift, squat, and clean. We will occasionally discuss a sports medicine, exercise, or nutrition article. Workouts will take anywhere from 20 to 40 minutes after the skills portion.

As everyone knows, sticking to regular exercise is extremely difficult to do alone. Since everyone participating in this curriculum should be doing these workouts, I strongly encourage you to find at least one partner, or small group, that you regular workout with to maintain consistent accountability.

\section{The Reading}

I will be occasionally posting articles on the MFC GroupMe for you to read. There will never be a test or other form of official accountability. However, there will be benefit to you and your patients in reading these articles. We will also discuss some of the posted material at FDFF as mentioned above. However, reading will not pertain to only "physical" fitness; it will include (but not be limited to) mental fitness, emotional fitness, spiritual fitness, and financial fitness (Remember how I defined fitness as not being limited by one's inability to participate in life's opportunities? So yes, this includes some financial fitness as well). Below, you will find a list of recommended reading and podcasts. It's a short list, but a very motivational and helpful list.

\section{Books:}

Bergeron, B. (2017). Chasing excellence: A story about building the world's fittest athletes. Carson City, NV: Lioncrest Publishing.

Campbell, T.C., Campbell, T.M. (2017). The China study: Revised and expanded edition: The most comprehensive study of nutrition ever conducted and the startling implications for diet, weight loss, and long-term health. Dallas, Texas: BenBella Books.

Dahle, J.M. (2014). The white coat investor: A Doctor's guide to personal finance and investing. United States of America: White Coat Investor LLC. 


\section{KANSAS JOURNAL of MEDICINE}

INCREASING RESIDENT PHYSICIAN WELL-BEING

continued.

Hutchinson, A. Which comes first, cardio or weights?: Fitness myths, training truths, and other surprising discoveries from the science of exercise. New York, NY: William Morrow Paperbacks.

Pollan, M. (2009). In defense of food: An eater’s manifesto. New York, NY: Penguin Books.

Sanfilippo, D. (2012). Practical paleo: A customized approach to health and a whole-foods lifestyle (2nd ed.). Las Vegas, NV: Victory Belt Publishing.

The Book of Proverbs. Holy Bible: Containing the Old and New Testaments: King James Version. (2010). New York, NY: American Bible Society.

Wolf, R. (2017). Wired to eat: Turn off cravings, rewire your appetite for weight loss, and determine the foods that work for you. New York, NY: Harmony Books.

\section{Podcasts:}

Bergeron, B. (2018). Chasing Excellence.

Dahle, J. (2018). White Coat Investor.

One of the greatest things about this residency is how close everyone is and the support everyone tries to provide one another. It's not a rare experience to be on night call and have someone randomly bring you dinner, coffee, or snacks. We often get together over food and drink. This portion of the curriculum is to help all this food evolve from doughnuts and pastries into dishes of meats, vegetables, cheeses, etc. Now, don't get me wrong, I love myself a fresh doughnut and few things can pick me up like one, but we will all be so much better if these kinds of treats become the exception and not the rule.

There will also be occasional "Paleo Potlucks." These usually occur on a Saturday afternoon/evening, where we start with an optional group workout then dive into a plethora of delicious and healthy dishes washed down with one or two "paleo" beverages.

Also, I am not advocating everyone eat "Paleo" diets. Paleo is something I personally enjoy, but the goal of this portion in the curriculum is to get you closer to real food and further away from food that outlasts its package. You know, all that "eat healthy" stuff we tell our patients to do, but surprisingly suck at ourselves. Hopefully, through this pursuit, we can become better prescribers of real medicine - food. "Let food be thy medicine and medicine be thy food" - Hippocrates. 


\section{Example Workouts}

\section{continued.}

\section{Workout \#1}

Warm Up:

- 400-meter run

2 to 3 minutes dynamic mobility as needed (PRN)

\section{Workout of the Day (WOD)}

20 minutes as many reps as possible (AMRAP), with weighted vest if you have one:

- 10 pull-ups or ring rows

- 20 push-ups

- 30 squats

Post your scores and whether you used a weighted vest!

\section{Workout \#2}

Warm Up:

- 400-meter run

2 rounds:

- 5 eccentric hand-release push-ups

- 5 deep eccentric squats

2 to 3 minutes dynamic mobility PRN

\section{WOD:}

For time, 20-minute time cap:

- $\quad 1 / 2$ mile run

- $50,40,30,20,10$ of a doublet: Push-ups and squats

- $1 / 2$ mile run

Post your times!

\section{Workout $\# 3$}

Warm Up:

- 2 minutes jump rope

3 rounds:

- 10 second hollow rock hold

- 15 second Superman hold

- 2 deep hip flexor stretching lunges (each leg)

- 4 Jefferson curls

2 to 3 minutes of dynamic mobility PRN

2 to 3 minutes warming up to starting deadlift weight

\section{WOD}

Every minute on the minute (EMOM) to failure or max rounds of 20 :

- 1 deadlift*

- *First round starts at $65 \mathrm{lbs}$. for women and $135 \mathrm{lbs}$. for men - add $10 \mathrm{lbs}$. each round. If all 20 rounds completed, women will end with 225 lbs. and men with 325 lbs.

Post your weights! 